\title{
EFEITOS DE SISTEMAS DE PRODUÇÃO DE GRÃOS ENVOLVENDO PASTAGENS SOB PLANTIO DIRETO NOS ATRIBUTOS FÍSICOS DE SOLO E NA PRODUTIVIDADE ${ }^{(1)}$
}

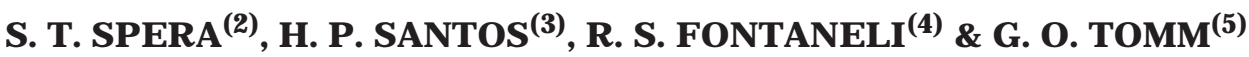

\begin{abstract}
RESUMO
A integração da lavoura com a pecuária altera a estrutura do solo, que, por sua vez, interfere nas características físicas na camada superficial. 0 objetivo deste trabalho foi avaliar os atributos físicos de solo e o rendimento de grãos num Latossolo Vermelho distrófico típico, em Passo Fundo (RS), oito anos após o estabelecimento (1993 a 2000) de sistemas de produção com culturas produtoras de grãos e forrageiras sob pastejo: (I) trigo/soja, aveia branca/soja e ervilhaca/ milho; (II) trigo/soja, aveia branca/soja e pastagem de aveia preta + ervilhaca/ milho; (III) pastagens perenes da estação fria (festuca + trevo branco + trevo vermelho + cornichão); (IV) pastagens perenes da estação quente (pensacola + aveia preta + azevém + trevo branco + trevo vermelho + cornichão), e (V) alfafa para feno, tratamento adicional acrescentado em 1994, com repetições em áreas contíguas ao experimento. As áreas sob os sistemas III, IV e V retornaram ao sistema I a partir do verão de 1996. Os tratamentos foram distri buídos em blocos ao acaso com quatro repetições. Amostras de solo também foram coletadas em fragmento de floresta subtropical ao lado do experimento, como testemunha da condição original do solo. A densidade do solo mostrou-se maior na camada subsuperficial $(10-15 \mathrm{~cm})$ do que na camada superficial $(0-5 \mathrm{~cm})$, enquanto para os valores de porosidade total e de macroporosidade ocorreu o inverso. Nos sistemas I, I I, III e IV, foram observados maiores valores de densi dade do solo e menores de porosidade total e macroporosidade na camada superficial, enquanto, no sistema V e em floresta subtropical, foram encontrados menores valores de densidade e maiores de porosidade total e de macroporosidade. Não houve diferenças entre os atri butos físicos para sistemas com e sem integração lavourapecuária. Não foram verificadas correlações significativas entre rendimento de culturas e atributos físicos de solo, exceto para macroporosidade do solo na cultura de soja na camada de 0-5 cm.
\end{abstract}

Termos de indexação: rotação de culturas, densidade do solo, porosidade total.

\footnotetext{
(1) Recebido para publicação em março de 2002 e aprovado em abril de 2004.

(2) Pesquisador da Embrapa Trigo - Centro Nacional de Pesquisa de Trigo. Caixa Postal 451, CEP $99001-970$ Passo Fundo (RS). E-mail: spera@cnpt.embrapa.br

(3) Pesquisador da Embrapa Trigo. Bolsista CNPq-PQ. E-mail: hpsantos@cnpt.embrapa.br

(4) Pesquisador da Embrapa Trigo, Professor Titular da FAMV, UniversidadedePasso Fundo- UPF. E-mail: renatof@cnpt.embrapa.br

(5) Pesquisador da Embrapa Trigo. E-mail: tomm@cnpt.embrapa.br
} 


\title{
SUMMARY: EFFECTS OF GRAIN PRODUCTION SYSTEMS INCLUDING PASTURES UNDER NO-TILLAGE ON SOIL PHYSICAL PROPERTIES AND YIELD
}

\begin{abstract}
Ley forming modifier soil structure, which, in turn, effects soil physical characteristics in the upper layer. The objective of this study was to eval uate soil physical attributes and grain yield in a typical dystrophic Red Latosol (Typic Haplorthox) located in Passo F undo county (RS), Brazil, after eight years of mixed production cultivation (1993 to 2000). The effects of production systems integrating grain production with winter annual and perennial pastures under no-tillage were assessed. Four mixed production systems were evaluated: system I (wheat/ soybean, white oat/ soybean, and common vetch/ corn); system II (wheat/ soybean, whiteoat/ soybean, and grazed black oat + grazed common vetch/ corn); system III [perennial cool season pastures (fescue + white cl over + red clover + bi rdsfoot trefoil)]; and system IV [perennial warm season pastures (bahiagrass + black oat + rye grass + white clover + red clover + bi rdsfoot trefoi I)]. System $V$ (alfalfa as hay crop) was established in an adjacent area in 1994. Theareas under systems III, IV, and V returned to system I after the 1996 summer. The treatments were arranged in a randomized complete bl ock design, with four replicates. As a control, physical soil parameter were evaluated in samples of a subtropical forest fragment adjacent to the experiment. Soil bulk density values werelower in thetop layer $(0-5 \mathrm{~cm})$ than in the deeper layer $(10-15 \mathrm{~cm})$, whilethereversewas observed for the total porosity and macroporosity. Systems I, II, III, and IV showed higher bulk density values and lower total porosity and macroporosity values in the surface layer (0$5 \mathrm{~cm}$ ). System $V$ and subtropical forest presented low bulk density and high total porosity and macroporosity values compared to the other treatments. It was observed no differences betwen physical attributes of integrated and non-integrated crop and livestock systems. No significant correlation was verified between crop yields and physical soil attributes, with exception of the soil macroporosity under soybean in the $0-5 \mathrm{~cm}$ layer.
\end{abstract}

Index terms: crop rotation, soil bulk density, total porosity.

\section{NTRODUÇÃO}

De modo geral, osolo mantido em estado natural, sob vegetação nativa, apresenta características físicas, como permeabilidade, estrutura, densidade do solo e porosidade, adequadas ao desenvolvimento normal de plantas (Andreola et al., 2000). Nessas condições, o vol ume de sol o explorado pelas raízes é relativamentegrande. À medida queo solo vai sendo submetido ao uso agrícola, as propriedades físicas sofrem alterações, geralmente desfavoráveis ao desenvol vimento vegetal.

Vários trabalhos demonstram que o tipo de expl oração agrícola afeta al guns atributos físi cos de solo (Anjos et al., 1994; Albuquerque et al., 1995; Andreola et al., 2000). Tem sido apregoado que sistema de rotação de culturas sob plantio direto, incluindo espécies com sistema radicular agressivo e com diferentes quantidades de fitomassa, pode alterar as propriedades físicas equímicas do solo ( $\mathrm{Da}$ Ros et al., 1997; Santos \& Tomm, 1999; Al buquerque et al., 2001). Por outro lado, a compactação de solo pode reduzir a produtividade de culturas, sendo a cultura de milho considerada sensível a esse processo (Albuquerqueet al., 2001). As propriedades densidade do solo, porosidade total, macro e microporosidade do solo têm sido usadas para indicar restrições ao desenvolvimento de plantas. No entanto, Unger \& Kaspar (1994) destacam que a compactação do solo reduz o crescimento de plantas principalmente quando o suprimento de água e nutrientes é insuficiente, fato observado quando as raízes desenvolvem-se acima de camadas compactadas.

Este trabal ho teve como obj etivo avaliar o efeito de sistemas de produção de grãos e de pastagens anuais de inverno e pastagens perenes, sob sistema plantio direto, após oito anos de cultivo, sobre os atributos físicos do solo e rendimento de culturas anuais.

\section{MATERIAL E MÉTODOS}

O experimento foi realizado em campo experimental do Centro Nacional de Pesquisa de Trigo (E mbrapa Trigo), situado no município de Passo Fundo, RS, (longitude $28^{\circ} 15^{\prime} \mathrm{S}$, latitude 52 ० $24^{\prime}$ 'W e altitude $684 \mathrm{~m}$ ) durante o período de 1993 a 2000, em Latossolo Vermel ho distrófico típico (Embrapa, 1999) textura muito argilosa e relevo suave ondulado. Os teores médios de argila, siltee areia na camada de 0-20 cm são, respectivamente, 720,130 e $150 \mathrm{~g} \mathrm{~kg}^{-1}$. O clima da região é do tipo 
Cfa, cuja temperatura média anual é $17,5^{\circ} \mathrm{C}$ e precipitação anual na faixa de $1.750 \mathrm{~mm}$, sem estação seca e bem distribuídos durante o ano (Brasil, 1973). Antes da instalação do experimento, a área foi cultivada por vários anos com a sucessão soja, no verão, e cevada ou trigo, no inverno, manejada por meio de preparo convencional de solo com aração e duas gradagens até 1981 e, a partir desse ano, por sistema plantio direto.

Os tratamentos consistiram originalmente em quatro sistemas de produção integrando grãos: (I) trigo/soja, aveia branca/soja e ervilhaca/milho (sem pastejo); (II ) trigo/soja, aveia branca/soja e pastagem de aveia preta + ervilhaca/milho; (III) pastagens perenes da estação fria (festuca + trevo branco + trevo vermel ho +cornichão); (IV) pastagens perenes da estação quente (pensacola + aveia preta +azevém + trevo branco + trevo vermelho + cornichão). O tratamento alfafa para feno (V) foi acrescentado adicionalmente em 1994 com repetições em áreas contíguas ao experimento. As áreas sob os sistemas I II, IV e V converteram-se em sistema I a partir do verão de 1996. A adubação de manutenção foi baseada nos valores observados nas análises químicas. Como testemunha, um fragmento de floresta subtropical com araucárias, adjacente ao experimento, acompanhando perpendicularmente todos os blocos, também foi amostrado, com o mesmo número de repetições, e sendo admitido apenas como referencial do estado estrutural do solo antes de ser submetido às alterações antrópicas. Todas as espécies, tanto de inverno como de verão, foram estabelecidas exclusivamente sob plantio direto, exceto no tratamento $\mathrm{V}$, que foi manejado por meio de preparo convencional do solo por aração e duas gradagens, uma única vez, em 1999. As pastagens anuais de inverno e perenes foram pastejadas por bovinos mestiços de raças européias, três vezes por safra, com carga animal equivalente a 15 a $20 \mathrm{UA} \mathrm{ha}^{-1}$ por $30 \mathrm{~h}$ cada pastejo.

Em abril de 1993, antes da semeadura das culturas de inverno, para instal ação do experimento, a camada de solo de $0-20 \mathrm{~cm}$ foi amostrada, e os resultados da análise de fertilidade foram: $\mathrm{pH}, 6,0$; $\mathrm{Al}^{3+}, 0,5 \mathrm{mmol}_{\mathrm{C}} \mathrm{dm}^{-3} ; \mathrm{Ca}^{2+}+\mathrm{Mg}^{2+}, 102,8 \mathrm{mmol}_{\mathrm{c}} \mathrm{dm}^{-3}$; matéria orgânica, $23,0 \mathrm{~g} \mathrm{~kg}^{-1} ; P, 5,3 \mathrm{mg} \mathrm{dm}^{-3}$; e $K$, $60 \mathrm{mg} \mathrm{dm}^{-3}$. Três anos antes da instalação do experimento, foi efetuada calagem com calcário dolomítico, com base no método SMP $(\mathrm{pH} 6,0)$. As parcelas semeadas com alfafa foram corrigidas novamente com 6,0 t ha-1 de cal cário (PRNT $100 \%$ ), para el evar o pH para 6,5, aplicadas em duas vezes: metade antes da aração e metade antes da gradagem. Em maio de 2000, foram coletadas amostras indeformadas de solo, em duplicata, com anéis de $5 \mathrm{~cm}$ de altura e volume de $207 \mathrm{~cm}^{3}$, nas profundidades de $0-5 \mathrm{~cm}$ e $10-15 \mathrm{~cm}$, destinadas às análises físicas de solo. A amostragem foi efetuada uma semana após chuva de 40 mm, em condições adequadas para col eta. Na análise de densidade do solo, foi usado o método do anel volumétrico. A porosidade total foi obtida pela percentagem de saturação em volume. A microporosidade foi considerada como o conteúdo do volume de água equilibrada na mesa de tensão a 0,60 m de coluna de água, enquanto a macroporosidade foi calculada por diferença de vol ume entre a porosidade total ea microporosidade, conforme E mbrapa (1997).

O delineamento experimental adotado foi de blocos ao acaso, com três repetições. A área de cada parcela foi de $400 \mathrm{~m}^{2}$. Os diversos sistemas de produção, integrando pastagens anuais de inverno e pastagens perenes com produção de grãos, foram comparados para cada um atributos físicos de solo estudados em determinada profundidade de amostragem. As profundidades de amostragem de sol o foram comparadas dentro de um mesmo sistema de produção. Todas as comparações foram efetuadas por meio de contrastes com um grau de liberdade. A significância dos contrastes de interesse com um grau de liberdade foi dada pel o teste $F$, levando em conta o desdobramento dos graus de liberdade do erro (SAS, 2003).

Os val ores médios para rendimento das culturas nas safras analisadas (verão, safra 1999/2000, e inverno, safra 2000) foram correlacionados com os valores de atributos físicos, por meio de correl ação de Pearson. Todas as análises estatísticas foram obtidas por meio de programa SAS, versão 8.2 (SAS, 2003).

\section{RESULTADOS E DISCUSSÃO}

\section{Densidade do solo}

Os sistemas de produção de grãos em pastagens apresentaram diferenças de densidade do solo (Quadro 1). Os sistemas I ell apresentaram maiores valores para densidade do solo, em comparação ao sistema V, nas camadas de 0-5 e 10-15 cm; o sistema II mostrou maior valor para densidade do solo, em relação aos sistemas III eIV, na camada de 0-5 cm, enquanto os sistemas III e IV apresentaram maior valor para densidade do solo, em relação ao sistema $V$, apenas na camada de $10-15 \mathrm{~cm}$. Deve-se ressaltar queosistema I foi destinado exdusivamente à produção de grãos, desde 1993, não mostrando diferenças entre as médias para densidade do solo, quando comparado com os sistemas III e IV, que foram transformados de pastagens em lavouras de produção de grãos a partir do verão de 1996, e para o sistema II, que vinha sendo pastejado três vezes durante cada inverno, desde 1993.

Por sua vez, a floresta subtropical, querepresenta a condição estrutural original do solo, teve menor densidade do solo (Quadro 1) em relação a todos os sistemas estudados nas camadas de 0-5 e 10-15 cm. Resultados semel hantes foram obtidos por Anjos et 
al. (1994), que relacionaram a densidade de solo de quatro classes de solos de Santa Catarina, em floresta subtropical com araucárias $\left(0,92 \mathrm{Mg} \mathrm{m}^{-3}\right)$, em lavouras com preparo convencional de solo $\left(1,06 \mathrm{Mg} \mathrm{m}^{-3}\right)$ e em lavouras sob sistema plantio direto $\left(1,13 \mathrm{Mg} \mathrm{m}^{-3}\right)$, na camada de $0-20 \mathrm{~cm}$ de um Latossolo Vermel ho-Amarelo argiloso.
A menor densidade do solo nas duas camadas avaliadas, no sistema $\mathrm{V}$ em relação aos demais sistemas agrícolas, pode ser atribuída não só ao revolvimento com arado de discos, efetuado em setembro de 1999, como também à ausência de pisoteio animal, cujos efeitos normalmente se restringem à camada superficial. Em estudo

Quadro 1. Valores de densidade do solo e porosidade total nas camadas de solo de 0-5 e $10-15 \mathrm{~cm}$ de profundidade, determinados após as culturas de verão, em cinco sistemas de produção e na floresta

\begin{tabular}{|c|c|c|c|}
\hline \multirow{2}{*}{ Sistema de produção } & \multicolumn{3}{|c|}{ Profundidade } \\
\hline & $0-5 \mathrm{~cm}$ & $10-15 \mathrm{~cm}$ & $0-5 \times 10-15 \mathrm{~cm}$ \\
\hline & \multicolumn{2}{|c|}{ Densidade do solo $\left(\mathrm{Mg} \mathrm{m}^{-3}\right)$} & Contrastes entre profundidade $(\mathrm{P}>\mathrm{F})$ \\
\hline Sistema I & 1,35 & 1,50 & $* *$ \\
\hline Sistema II & 1,38 & 1,52 & $* *$ \\
\hline Sistema III & 1,29 & 1,47 & $* *$ \\
\hline Sistema IV & 1,30 & 1,49 & $* *$ \\
\hline Sistema V & 1,22 & 1,38 & $* *$ \\
\hline \multirow[t]{2}{*}{ Floresta (F) } & 1,05 & 1,17 & ns \\
\hline & \multicolumn{2}{|c|}{ Contrastes entre sistemas } & \\
\hline$|\times| \mid$ & ns & ns & \\
\hline$|\times|||$ & ns & ns & \\
\hline $\mathrm{I} \times \mathrm{IV}$ & ns & ns & \\
\hline $\mathrm{I} \times \mathrm{V}$ & $* *$ & $* *$ & \\
\hline $\mathrm{I} \times \mathrm{F}$ & $* *$ & $* *$ & \\
\hline$\|\times\| \|$ & $*$ & ns & \\
\hline II x IV & $*$ & ns & \\
\hline $\mathrm{II} \times \mathrm{V}$ & $* *$ & $* *$ & \\
\hline $\mathrm{II} \times \mathrm{F}$ & $* *$ & $* *$ & \\
\hline III $x \mathrm{IV}$ & ns & ns & \\
\hline $111 \times \mathrm{V}$ & ns & $* *$ & \\
\hline $\mathrm{III} \times \mathrm{F}$ & $* *$ & $* *$ & \\
\hline IV $\times \mathrm{V}$ & ns & $* *$ & \\
\hline $\mathrm{IV} \times \mathrm{F}$ & ** & $* *$ & \\
\hline \multirow[t]{2}{*}{$V \times F$} & $* *$ & $* *$ & \\
\hline & \multicolumn{2}{|c|}{ Porosidade total $\left(\mathrm{m}^{3} \mathrm{~m}^{-3}\right)$} & Contrastes entre profundidades $(\mathrm{P}>\mathrm{F})$ \\
\hline Sistema I & 0,492 & 0,434 & $* *$ \\
\hline Sistema II & 0,476 & 0,423 & $* *$ \\
\hline Sistema III & 0,510 & 0,447 & $* *$ \\
\hline Sistema IV & 0,507 & 0,434 & $* *$ \\
\hline \multirow{3}{*}{ Floresta (F) } & 0,536 & 0,478 & $* *$ \\
\hline & 0,594 & 0,548 & ns \\
\hline & \multicolumn{2}{|c|}{ Contrastes entre sistemas } & \\
\hline$|\times| \mid$ & ns & ns & \\
\hline$|\times|||$ & ns & ns & \\
\hline $1 \times 1 V$ & ns & ns & \\
\hline $\mathrm{I} \times \mathrm{V}$ & $* *$ & $* *$ & \\
\hline $\mathrm{I} \times \mathrm{F}$ & $* *$ & $* *$ & \\
\hline $11 \times \| 11$ & $*$ & ns & \\
\hline II x IV & ns & ns & \\
\hline $\mathrm{II} \times \mathrm{V}$ & $* *$ & $* *$ & \\
\hline$I I \times F$ & $* *$ & $* *$ & \\
\hline $111 \times 1 V$ & ns & ns & \\
\hline $111 \times V$ & $*$ & $*$ & \\
\hline$I I I \times F$ & $* *$ & $* *$ & \\
\hline$I V \times V$ & ns & $* *$ & \\
\hline$I V \times F$ & $* *$ & $* *$ & \\
\hline$V \times F$ & $*$ & $* *$ & \\
\hline
\end{tabular}

ns = não-significativo; * =significativo a 5\%; ** =significativo a 1\%. I: trigo/soja, aveia branca/soja e ervilhaca/milho; II : trigo/soja, aveia branca/soja e pastagem de aveia preta + ervilhaca/milho; III: trigo/soja, aveia branca/soja e ervilhaca/milho após pastagem perene de inverno; IV: trigo/soja, aveia branca/soja e ervilhaca/milho após pastagem perene de verão; V: trigo/soja, aveia branca/ soja e ervilhaca/milho após alfafa; e F : floresta subtropical com araucária. 
desenvolvido por Da Ros et al . (1997) sobresistemas de manejo de solo, em Latossolo Vermelho-Escuro distrófico argiloso, no Rio Grande do Sul, durante cinco anos, foi verificado que a menor densidade do solo ocorreu em tratamentos submetidos ao preparo convencional com aração e gradagem, em relação ao plantio direto, em três camadas estudadas entre 0 e $21 \mathrm{~cm}$.

Considerando que a densidade do solo tem sido um dos atributos usados para avaliação do estado estrutural do solo, as condições verificadas nos quatro primeiros sistemas permitem afirmar que não houve compactação de solo na superfície. Entretanto, os valores observados na camada subsuperficial desses sistemas encontram-se acima daqueles considerados, por Resende (1995), como críticos para Latossolos argilosos com umidade abaixo de $50 \%$ (com densidade de solo acima de $1,40 \mathrm{Mg} \mathrm{m}^{-3}$ ), o que caracteriza camada compactada. Todavia, de acordo com Bowen (1981), para solos argilosos, o valor de densidade que pode ser considerado crítico quando em estado de capacidade de campo é de $1,55 \mathrm{Mg} \mathrm{m}^{-3}$.

Albuquerque et al. (1995) observaram, em L atossolo Vermel ho-E scuro distrófico argil oso do Rio Grande do Sul, que a sucessão trigo/soja propiciou maior densidade do solo $\left(1,21 \mathrm{Mg} \mathrm{m}^{-3}\right)$ na camada de 1,0-8,6 cm que as rotações: trigo/soja, aveia preta + ervilhaca/milho (1,14 $\left.\mathrm{Mg} \mathrm{m}^{-3}\right)$ e aveia preta/soja; aveia preta/soja, aveia preta/soja e trigo/soja $\left(1,14 \mathrm{Mg} \mathrm{m}^{-3}\right)$.

A densidade do solo em todos os sistemas de produção estudados foi maior em subsuperfície (10$15 \mathrm{~cm}$ ), exceto para floresta subtropical (Quadro 1). Albuquerqueet al. (2001) nãoverificaram diferenças entre camadas em experimento realizado com sistemas de manejo de solo, em Nitossolo Vermel ho argi loso no estado de Santa Catarina. Por outrolado, no presente estudo, a densidade do solo foi menor na camada de 0-5 cm, em relação à camada de 10$15 \mathrm{~cm}$, indicando provável compactação residual do solo nesta profundidade, resultante de operações anteriores de preparo de sol o com aração e gradagem (Spera et al., 2002). Resultados semel hantes foram obtidos por Albuquerque et al. (1995), que observaram ter a densidade do solo aumentado da camada de 1,0-8,6 cm, variando de 1,14 (floresta) e $1,21 \mathrm{Mg} \mathrm{m}^{-3}$ (lavoura), a 1,25 (floresta) e 1,28 $\mathrm{Mg} \mathrm{m}^{-3}$ (lavoura), na camada de 8,6-16,2 cm. No caso da floresta, a variação seria por causas naturais.

Derpsch et al. (1986), Trein et al. (1991) e Albuquerque et al. (2001) observaram que, em plantio direto, a densidadedosoloé mai or na camada superficial e decresce nas maiores profundidades, mas os autores consideraram como camada superficial a de $0-20 \mathrm{~cm}$ e, como subsuperficial, a camada BA ou o horizonte Bw de Latossolos Roxos abaixo de $20 \mathrm{~cm}$. Nesses casos, os autores localizaram a camada compactada entre 10 e $20 \mathrm{~cm}$ de profundidade, coincidindo com o pé-de-grade ou pé-de-arado. Assim, no presente trabalho, se for desconsiderado o critério de nomenclatura de camadas, foi observado o mesmo comportamento de compactação do solo para sistema plantio direto.

Ao contrário do que se poderia esperar, o pisoteio de animais nas parcelas com pastagens anuais de inverno e perenes, na lotação e freqüência adotada, mesmo que em condições de solo úmido e de biomassa da pastagem similares, não levou, principalmente na camada de $0-5 \mathrm{~cm}$, à obtenção de maiores valores para densidade do solo nos tratamentos III, IV e V, quando comparados ao do sistema I, dedicado exclusivamente à produção de grãos. De acordo com Albuquerque et al. (2001), em sistemas de integração lavoura-pecuária, a presença de raízes de gramíneas melhoram a estrutura do solo, amenizando o impacto do pisoteio. No entanto, no tratamento II, o maior valor para densidade do solo na camada superficial pode ser atribuído principalmente ao efeito do pisoteio animal, combi nado ao trânsito de máquinas e pisoteio animal, conforme constataram também Anjos et al. (1994).

\section{Porosidade total do solo}

Quanto à porosidade total do solo, alguns sistemas de produção estudados apresentaram diferenças entre si e entre as duas profundidades estudadas em todos tratamentos submeti dos à ação antrópica (Quadro 1). O sistema V apresentou maior porosidade total do que os sistemas I, II e III para ambas as camadas (Quadro 1). O sistema III apresentou maior porosidade total que o sistema II somente na camada de $0-5 \mathrm{~cm}$ (Quadro 1). Por sua vez, a floresta subtropical mostrou mai or porosidade total em relação a todos os sistemas, em ambas as camadas (Quadro 1), ressaltando a importância dos resíduos vegetais na estruturação dos solos. O sistema $\mathrm{V}$ mostrou mai or porosidade total que o sistema IV apenas na camada de $10-15 \mathrm{~cm}$ (Quadro 1). As diferenças podem ser atribuídas ao efeito de presença de gramíneas forrageiras no sistema, à intensidade variável de trânsito de máquinas e ao revolvimento do solo. No caso do sistema $\mathrm{V}$, a maior porosidade total em relação aos demais sistemas pode ser relacionada com a menor densidade do solo, podendo ser atribuída ao efeito residual do revolvimento do solo.

Albuquerque et al. (1995) observaram que a sucessão trigo/soja mostrou menor porosidade total $\left(0,54 \mathrm{~m}^{3} \mathrm{~m}^{-3}\right)$ na camada de 1,0-8,6 cm que as rotações: trigo/soja, aveia preta/soja e aveia preta + ervilhaca/milho $\left(0,57 \mathrm{~m}^{3} \mathrm{~m}^{-3}\right)$ e aveia preta/soja, aveia preta/soja e trigo/soja $\left(0,57 \mathrm{~m}^{3} \mathrm{~m}^{-3}\right)$. Da Ros et al. (1997) observaram, em solos sob preparo convencional com aração e gradagem, maior por osidade total em duas camadas (0-7 e 7-14 cm), em relação ao plantio direto. Anjos et al. (1994) não encontraram diferenças entre os tratamentos nas 
lavouras com preparo convencional de solo e lavouras sob sistema plantio direto, para porosidade total, na camada de $0-20 \mathrm{~cm}$.

Al buquerque et al. (2001) verificaram maior valor para porosidadetotal em sol osob floresta subtropical, em comparação aos tratamentos sob ação antrópica. $\mathrm{Na}$ condição de floresta natural e sob plantio direto (sistemas I, II I III e IV), quando o solo permaneceu constantemente coberto por material vegetal, ocorreu intensa atividade biológica, resultando em maior formação e estabilização de agregados.

Quanto à diferença entreos valores de porosidade total, ao comparar as duas profundidades de amostragem, observou-se diferença entre camadas em todos os sistemas de produção estudados, com exceção da floresta subtropical (Quadro 1). A porosidade total diminuiu da camada de $0-5 \mathrm{~cm}$ para a camada de $10-15 \mathrm{~cm}$, indicando degradação da estrutura do solo. I sso ficou mais evidente com a redução da macroporosidade. Resultados semelhantes foram obtidos por Albuquerque et al. (1995), trabalhando com um Latossolo Vermelho-Escuro argil oso. Todavia, comparativamente ao observado neste trabalho, esses autores (2001) encontraram tendência inversa em Nitossolo Vermelho.

Maior valor para porosidade total na camada superficial $(0-5 \mathrm{~cm})$ reflete menor densidade do solo epode ser atribuída ao acúmulo de material orgânico na camada superficial, considerando o manejo do sol o sem revolvimento (Derpsch et al., 1986), enquanto menor porosidade total na camada abaixo de $5 \mathrm{~cm}$ reflete maior densidade do solo e é provavel mente explicada por modificações na estrutura advindas do pisoteio animal ou trânsito de máquinas ou implementos.

\section{Microporosidade}

Dentre os sistemas de produção estudados, houve diferenças entre as médias para microporosidade (Quadro 2). O sistema V apresentou mai or valor para microporosidade do que os sistemas I, II e IV em ambas as camadas. A condição original de estruturação do solo (floresta subtropical) indica maior valor de microporosidade (Quadro 2), em relação aos sistemas I, II, III, IV e V, somente na camada de $0-5 \mathrm{~cm}$. A maior microporosidade, no sistema $V$, pode ser resultado das alterações estruturais promovidas pelo revolvimento de solo, em 1999. Isso, porém, não foi verdadeiro, em relação ao sistema III. Houve diferenças entre as profundidades do sol o para microporosidadesomente em um dos sistemas de produção estudados. No sistema V, a micropor osidade aumentou da camada de 0-5 cm para a camada de $10-15 \mathrm{~cm}$.

Verificou-se que os trabalhos com sistemas de manejo de sol o que incluíam rotação de culturas de Al buquerque et al . (1995) e de Andreola et al . (2000), em um Nitossolo Vermel ho argiloso de Santa Catarina, não mostraram diferenças entre os tratamentos para microporosidade. Não houve diferenças entre os valores de microporosidade nos sistemas de culturas anuais e de pastagens perenes, evidenciando que, em sistemas de integração lavoura-pecuária, o pisoteio animal, em lotação adequada, não promove alter ações adicionais neste atributo do solo, além daquelas advindas do trânsito de máquinas.

\section{Macroporosidade}

$\mathrm{Na}$ camada de 0-5 cm, a floresta subtropical e o sistema IV apresentaram maiores valores para macroporosidade que o sistema II (Quadro 2). O intenso trânsito de máquinas e o pisoteio deanimais, no sistema II, embora ocorridos em momentos distintos, podem ter contribuído para a redução da macroporosidade nessa camada (Derpsch et al., 1986). I sso indica que a macroporosidade é susceptível a mudanças impostas pelo manejo de solo, fato também constatado por Trein et al. (1991) e Albuquerque et al. (2001).

Apenas para alguns tratamentos houvediferenças entre as médias de macroporosidade (Quadro 2). A condição original de estruturação do solo (floresta subtropical) também indica maior valor para macroporosidade, em comparação aos sistemas sob ação antrópica I, II , III, IV e V, na camada de 10$15 \mathrm{~cm}$. Constata-se que as operações de mobilização do solo, sob manejo convencional, e, posteriormente, sob sistema plantio direto, provocaram redução na macroporosidade, com efeitos negativos para a aeração do solo.

F oram observadas diferenças de macroporosi dade entre profundidades de amostragem desolo detodos os sistemas de produção, exceto na floresta subtropical. A macroporosidade, nos sistemas submetidos à ação antrópica, diminuiu da camada de 0-5 cm para a camada de $10-15 \mathrm{~cm}$ (Quadro 2). A densidade do sol o ea microporosidadeaumentaram da camada superficial para a camada mais profunda e, em conseqüência, para porosidade total e macroporosidade ocorreu o inverso, uma vez que esses atributos são dependentes entre si. Assim como para microporosidade, não houve diferenças entre os val ores de macropor osidade de sistemas de culturas anuais e de pastagens perenes, exceto para a camada superficial dos tratamentos II e IV, indicando, neste caso, que, em sistemas de integração lavoura-pecuária, o pisoteio animal pode ocasionar alterações adicionais na macroporosidade do solo, além daquelas advindas do trânsito de máquinas.

\section{Efeitos do manejo nos atri butos físicos do solo}

Os atributos físicos de solo avaliados são interdependentes, assim, os efeitos do manejo de solo sobre eles valem para todos. Observa-se que, em caso de sistemas de produção de grãos com ou sem integração lavoura-pecuária, ocorreram maiores 
Quadro 2. Valores de microporosidade e macroporosidade nas camadas de solo de 0-5 e $10-15 \mathrm{~cm}$ de profundidade, determi nados após as culturas de verão, em cinco sistemas de produção e na floresta

\begin{tabular}{|c|c|c|c|}
\hline \multirow{2}{*}{ Sistema de produção } & \multicolumn{3}{|c|}{ Profundidade } \\
\hline & $0-5 \mathrm{~cm}$ & $10-15 \mathrm{~cm}$ & $0-5 \times 10-15 \mathrm{~cm}$ \\
\hline & \multicolumn{2}{|c|}{ Microporosidade $\left(\mathrm{m}^{3} \mathrm{~m}^{-3}\right)$} & Contrastes entre profundidade $(\mathrm{P}>\mathrm{F})$ \\
\hline $\begin{array}{l}\text { Sistema I } \\
\text { Sistema II } \\
\text { Sistema III } \\
\text { Sistema IV } \\
\text { Sistema V } \\
\text { Floresta (F) }\end{array}$ & $\begin{array}{l}0,363 \\
0,361 \\
0,368 \\
0,355 \\
0,388 \\
0,420\end{array}$ & $\begin{array}{l}0,367 \\
0,370 \\
0,384 \\
0,367 \\
0,417 \\
0,399\end{array}$ & $\begin{array}{l}\text { ns } \\
\text { ns } \\
\text { ns } \\
\text { ns } \\
* * \\
\text { ns }\end{array}$ \\
\hline Floresta (F) & \multicolumn{2}{|c|}{ Contrastes entre sistemas } & \\
\hline $\begin{array}{l}I \times I I \\
I \times I I I \\
I \times I V \\
I \times V \\
I \times F \\
I I \times I I I \\
I I \times I V \\
I I \times V \\
I I \times F \\
I I I \times I V \\
I I I \times V \\
I I I \times F \\
I V \times V \\
I V \times F \\
V \times F\end{array}$ & $\begin{array}{c}\mathrm{ns} \\
\mathrm{ns} \\
\mathrm{ns} \\
* \\
* \\
\mathrm{~ns} \\
\mathrm{~ns} \\
* \\
* * \\
\mathrm{~ns} \\
\mathrm{~ns} \\
* * \\
* * \\
* * \\
*\end{array}$ & $\begin{array}{l}\text { ns } \\
\text { ns } \\
\text { ns } \\
* * \\
\text { ns } \\
\text { ns } \\
\text { ns } \\
* * \\
\text { ns } \\
\text { ns } \\
\text { ns } \\
\text { ns } \\
* * \\
\text { ns } \\
\text { ns }\end{array}$ & \\
\hline$V \times F$ & \multicolumn{2}{|c|}{ Macroporosidade $\left(\mathrm{m}^{3} \mathrm{~m}^{-3}\right)$} & Contrastes entre profundidades $(\mathrm{P}>\mathrm{F})$ \\
\hline $\begin{array}{l}\text { Sistema I } \\
\text { Sistema II } \\
\text { Sistema III } \\
\text { Sistema IV } \\
\text { Sistema V } \\
\text { Floresta (F) }\end{array}$ & $\begin{array}{l}0,130 \\
0,114 \\
0,144 \\
0,153 \\
0,149 \\
0,174\end{array}$ & $\begin{array}{l}0,064 \\
0,053 \\
0,063 \\
0,070 \\
0,061 \\
0,149\end{array}$ & $\begin{array}{l}* * \\
* * \\
* * \\
* * \\
* * \\
\text { ns }\end{array}$ \\
\hline$|x| \mid$ & ns & ns & \\
\hline$|\times| 1 \mid$ & ns & ns & \\
\hline $\mathrm{I} \times \mathrm{IV}$ & ns & ns & \\
\hline $\mathrm{I} \times \mathrm{V}$ & ns & ns & \\
\hline $\mathrm{I} \times \mathrm{F}$ & ns & $* *$ & \\
\hline $11 \times 111$ & ns & ns & \\
\hline II $\times 1 V$ & $*$ & ns & \\
\hline $\begin{array}{l}I I \times V \\
I I \times F\end{array}$ & $\begin{array}{r}\text { ns } \\
*\end{array}$ & $\begin{array}{l}\text { ns } \\
* *\end{array}$ & \\
\hline III $x$ IV & ns & ns & \\
\hline III $\times \mathrm{V}$ & ns & ns & \\
\hline $1 I I \times F$ & ns & ** & \\
\hline IV $\times \mathrm{V}$ & ns & ns & \\
\hline $\mathrm{IV} \times \mathrm{F}$ & ns & $* *$ & \\
\hline$V \times F$ & ns & $* *$ & \\
\hline
\end{tabular}

ns = não-significativo; * =significativo a 5\%; ** =significativo a 1\%. I: trigo/soja, aveia branca/soja e ervilhaca/milho; II: trigo/soja, aveia branca/soja e pastagem de aveia preta + ervilhaca/milho; III: trigo/soja, aveia branca/soja e ervilhaca/milho após pastagem perene de inverno; IV: trigo/soja, aveia branca/soja e ervilhaca/milho após pastagem perene de verão; V: trigo/soja, aveia branca/ soja e ervilhaca/milho após alfafa; e F : floresta subtropical com araucária.

valores para densidade do sol o e macroporosidade e menores de porosidade total e microporosidade, em ambas as camadas estudadas, em comparação aos valores para floresta subtropical e cultura de alfafa para feno (Quadros 1 e2). A área ondese instal ou o experimento foi submetida, durante longo período, ao preparo convencional com aração e gradagens.
Isso pode explicar a diferença entre os valores de cada atributo físico, verificada em todos os tratamentos, entre as camadas de 0-5 e 10-15 cm, indicando presença de efeito residual de pé-de-arado ou pé-de-grade. Normalmente, no Rio Grande do Sul, a profundidade de mobilização do solo pelo preparo convencional de solo raramente se 
aprofundava abaixo de $10 \mathrm{~cm}$ (Denardin \& Kochhann, 1993). A menor densidade do solo, no sistema $\mathrm{V}$, pode ser atribuída ao revolvimento com arado de discos, efetuado em setembro de 1999, que se fez necessário na área, em decorrência da infestação de plantas espontâneas de fol ha larga.

A seqüência de operações de semeadura, tratos fitossanitários e colheita, nos tratamentos sem a inclusão de pastagens, foi mais intensa que nos tratamentos com rotação com pastagens. E sse fato deve ter colaborado para a obtenção de maiores valores de densidade do solo e macroporosidade, e menores de porosidadetotal e microporosidadeentre esses tratamentos, mesmo considerando que al guns valores não apresentam diferenças estatísticas (Salviano, 1981).

O pisoteio, nos tratamentos submetidos a pastagens anuais, não parece ter afetado, após quatro anos, os atributos físicos de solo o suficiente para promover prejuízos ao rendimento de culturas. Carvalho (1976) verificou que pesadas cargas de animal por pouco tempo podem ser suficientes para provocar aumento da densidade do sol o einfluir nos demais atributos físicos; entretanto, após cessado o pisotei o, ocorreria regeneração da densi dade do sol o. Oliveira et al. (2000) e Macedo (2001) apontaram que, em sistemas de produção com integração lavoura-pecuária, o rendimento de culturas anuais após a pastagem tendia a ser maior que na ausência de rotação com pastagem.
Neste trabalho, não houve intenção, entretanto, de estabelecer comparações entre as alterações promovidas pel os tratamentos e o estado natural do sol o observado na condição de floresta subtropical, uma vez que o experimento foi instalado em área que já se encontrava submetida à ação antrópica, sendo, portanto, impossível avaliar as alterações dos tratamentos promovidas nas condições originais de estruturação. Os dados de condição original, porém, são úteis para balizar até que ponto os valores dos atributos físicos poderiam atingir para obter uma completa recuperação da estrutura.

\section{E feitos no rendimento de grãos das culturas}

Os rendimentos das cul turas de verão (safra 1999/ 2000) e de inverno (na safra 2000) foram correlacionados com os atributos físicos. As médias de rendimento para as culturas de aveia branca e trigo (inverno) e soja e milho (verão) não diferiram entre os sistemas, para cada cultura. Como, porém, houve variações de rendimentos entre as parcelas, com val ores oscilando de 2.876 a $5.115 \mathrm{~kg} \mathrm{ha}^{-1}$ para aveia branca, de 1.530 a $2.928 \mathrm{~kg} \mathrm{ha}^{-1}$ para trigo, de 2.187 a $3.782 \mathrm{~kg} \mathrm{ha}^{-1}$ para soja e de 7.388 a $10.675 \mathrm{~kg} \mathrm{ha}^{-1}$ para milho, foram estabelecidas correlações entre os valores de atributos físicos de solo e rendimentos de culturas, para cada parcela (Quadro 3). Exceto para macroporosidade do solo em cultura de soja na camada de $0-5 \mathrm{~cm}$, não se verificou correlação significativa entre os valores

Quadro 3. Coeficientes de correlação de Pearson ( $r$ ), probabilidades > F, graus de liberdade para quatro culturas, em relação a quatro atributos de solos em duas profundidades

\begin{tabular}{|c|c|c|c|c|c|c|}
\hline \multirow{3}{*}{ Cultura } & \multicolumn{6}{|c|}{ Profundidade } \\
\hline & \multicolumn{3}{|c|}{0 a $5 \mathrm{~cm}$} & \multicolumn{3}{|c|}{10 a $15 \mathrm{~cm}$} \\
\hline & Coeficiente & Prob. $>$ F & G.L. & Coeficiente & Prob. $>F$ & G.L. \\
\hline & \multicolumn{6}{|c|}{ Densidade do solo } \\
\hline \multirow[t]{2}{*}{$\begin{array}{l}\text { Aveia branca } \\
\text { Trigo } \\
\text { Soja } \\
\text { Milho }\end{array}$} & $\begin{array}{l}-0,18 \\
-0,27 \\
-0,35 \\
-0,06\end{array}$ & $\begin{array}{l}0,52 \\
0,33 \\
0,06 \\
0,83\end{array}$ & $\begin{array}{l}15 \\
15 \\
30 \\
15\end{array}$ & $\begin{array}{r}-0,14 \\
0,26 \\
0,07 \\
0,10\end{array}$ & $\begin{array}{l}0,62 \\
0,35 \\
0,72 \\
0,71\end{array}$ & $\begin{array}{l}15 \\
15 \\
30 \\
15\end{array}$ \\
\hline & \multicolumn{6}{|c|}{ Porosidade total } \\
\hline \multirow[t]{2}{*}{$\begin{array}{l}\text { Aveia branca } \\
\text { Trigo } \\
\text { Soja } \\
\text { Milho }\end{array}$} & $\begin{array}{l}0,18 \\
0,25 \\
0,33 \\
0,02\end{array}$ & $\begin{array}{l}0,52 \\
0,37 \\
0,07 \\
0,93\end{array}$ & $\begin{array}{l}15 \\
15 \\
30 \\
15\end{array}$ & $\begin{array}{l}0,15 \\
-0,23 \\
-0,09 \\
-0,22\end{array}$ & $\begin{array}{l}0,61 \\
0,41 \\
0,64 \\
0,42\end{array}$ & $\begin{array}{l}15 \\
15 \\
30 \\
15\end{array}$ \\
\hline & \multicolumn{6}{|c|}{ Microporosidade } \\
\hline \multirow[t]{2}{*}{$\begin{array}{l}\text { Aveia branca } \\
\text { Trigo } \\
\text { Soja } \\
\text { Milho }\end{array}$} & $\begin{array}{r}0,14 \\
-0,14 \\
-0,36 \\
-0,30\end{array}$ & $\begin{array}{l}0,61 \\
0,61 \\
0,06 \\
0,28\end{array}$ & $\begin{array}{l}15 \\
15 \\
30 \\
15\end{array}$ & $\begin{array}{l}-0,01 \\
-0,14 \\
-0,27 \\
-0,25\end{array}$ & $\begin{array}{l}0,99 \\
0,62 \\
0,15 \\
0,36\end{array}$ & $\begin{array}{l}15 \\
15 \\
30 \\
15\end{array}$ \\
\hline & \multicolumn{6}{|c|}{ Macroporosidade } \\
\hline $\begin{array}{l}\text { Aveia branca } \\
\text { Trigo } \\
\text { Soja } \\
\text { Milho }\end{array}$ & $\begin{array}{l}0,08 \\
0,31 \\
0,49 \\
0,21\end{array}$ & $\begin{aligned} & 0,77 \\
& 0,25 \\
&< 0,01 * * \\
& 0,45\end{aligned}$ & $\begin{array}{l}15 \\
15 \\
30 \\
15\end{array}$ & $\begin{array}{r}0,29 \\
-0,11 \\
0,24 \\
0,11\end{array}$ & $\begin{array}{l}0,29 \\
0,68 \\
0,18 \\
0,71\end{array}$ & $\begin{array}{l}15 \\
15 \\
30 \\
15\end{array}$ \\
\hline
\end{tabular}

** Significativo a $1 \%$. 
para os atributos de solo densidade do solo, porosidade total, macro e microporosidade e rendimentos de culturas de aveia branca, trigo, soja emilho. A correlação positiva entremacroporosidade da camada de $0-5 \mathrm{~cm}$ e rendimento de soja pode ser atribuída à maior aeração em conseqüência do aumento da macroporosidade, favorecendo a fixação biológica de $\mathrm{N}_{2}$ (Siqueira et al., 1994).

Torres \& Saraiva (1999) observaram, para a cultura da soja sob plantio direto, redução de rendimento em virtude do aumento da densidade do sol ona camada de $0-10 \mathrm{~cm}$ de um L atossolo Roxo, de Londrina, PR. Derpsch et al. (1986) verificaram maior valor para densidade do sol o em plantio direto, ao comparar esse manejo com cultivo mínimo e preparo convencional desolo, porém os rendimentos de trigo e soja foram mai ores sob plantio direto. Tais autores concluíram que o não revolvimento do solo, combinado com sistemas de rotação de culturas, mostrou-se eficiente na redução dos efeitos de compactação de solos.

Deacordo com McGarry et al . (2000), a densidade do sol o tem si do o atributo mais comum de aval iação de compactação de solos em ensaios sobre plantio direto e preparo convencional de solo. Todavia, por ser uma medida estática, não é sensível para detectar a condição física do solo, não só por constituir característica de uma mistura de fatores de ponderação desconhecida de natureza mecânica, biológica, física, química e de matéria orgânica, mas também por oferecer valor único para diferentes condições estruturais do solo. Assim, fatores deoutra natureza, como, por exemplo: química e biológica, podem estar afetando mais orendimento de culturas do que os atributos físicos de solo.

\section{CONCLUSÕES}

1. Os sistemas agrícolas e de integração lavourapecuária sem revolvimento do solo afetaram os atributos físicos do solo em relação à condição original sob floresta subtropical.

2. O cultivo de alfafa para produção de feno, seguido por culturas de grãos em semeadura direta, apresentou, em geral, menor densidade do solo em relação aos demais sistemas agrícolas, possivel mente decorrente do revolvimento do sol o efetuado.

3. Nas condi ções estudadas, não há evidências de que o pisotei o tenha interferido negativamente nos atributos físicos, exceto por um ligeiro aumento na densidade do sol o na camada superficial no sistema lavoura-pecuária com pastagem anual de inverno em relação às áreas utilizadas com pastagens perenes sucedidas por sistemas agrícolas.

4. A densidade dosol oaumentou em profundidade nas camadas avaliadas em todos os sistemas de produção agropecuária, ocorrendo, em conseqüência, o inverso para porosidade total e macroporosidade.
A microporosidadeaumentou da camada superficial para a camada mais profunda do solo sob cultivo de alfafa para produção de feno seguido por culturas de grãos em semeadura direta, em decorrência do revolvimento.

5. Em geral, os atributos físicos do solo não interferiram significativamente no rendimento das culturas avaliadas.

\section{LITERATURA CITADA}

ALBUQUERQUE, J.A.; REINERT, D.J .; FIORIN, J.E.; RUEDELL, J .; PETRERE, C. \& FONTINELLI, F. Rotação de culturas e sistemas de manejo do solo: efeito sobre a forma da estrutura do solo ao final de sete anos. R. Bras. Ci. Solo, 19:115-119, 1995.

ALBUQUERQUE, J .A.; SANGOI, L. \& ENDER M. Efeitos da integraçãolavoura-pecuária nas propriedades físicas do solo e características da cultura do milho. R. Bras. Ci. Solo, 25:717-723, 2001.

ANDREOLA, F.; COSTA, L.M. \& OLSZEVSKI, N. Influência da cobertura vegetal de inverno e da adubação orgânica e, ou, mineral sobre as propriedades físicas de uma Terra Roxa Estruturada. R. Bras. Ci. Solo, 24:857-865, 2000.

ANJ OS, J .T.; UBERTI, A.A.A.; VIZZOTTO, V.J .; LEITE, G.B. \& KRIEGER, M. Propriedades físicas em solos sob diferentes sistemas de uso e manejo. R. Bras. Ci. Solo, 18:139-145, 1994.

BOWEN, H.D. Alleviating mechanical impedance. In: ARKIN, G.F. \& TAYLOR, H.M., eds. Modifying the root environment to reduce crop stress. St. J oseph, American Society of Agricultural Engineers, 1981. p.18-57. (ASAE Monograph, 4)

BRASIL. Ministério da Agricultura. Divisão de Pesquisa Pedológica. Levantamento de reconhecimento dos solos do estado do Rio Grande do Sul. Recife, MA-DPP/SA-DRNR/ INCRA-RS, 1973. 431p.

CARVALHO, S.R. Influência de dois sistemas de manejo de pastagens na compactação de uma Terra Roxa Estruturada. Piracicaba, Escola Superior de Agricultura "Luiz de Queiroz", 1976. 89p. (Tese de Mestrado)

DA ROS, C.O.; SECCO, D.; FIORIN, J .E.; PETRERE, C.; CADORE, M.A. \& PASA, L. Manejo do solo a partir de campo nativo: efeito sobre a forma e estabilidade da estrutura ao final de cinco anos. R. Bras. Ci. Solo, 21:241247, 1997.

DERPSCH, R.; SIDIRAS, N. \& ROTH, C.H. Results of studies made from 1977 to 1984 to control erosion by cover crops and no-tillage techniques in Paraná, Brazil. Soil Till. Res., 8:253-263. 1986.

DENARDIN, J .E. \& KOCHHANN, R.A. Requisitos para a implantação e a manutenção do sistema plantio direto. In: Empresa Brasileira de Pesquisa Agropecuária - Centro Nacional de Pesquisa de Trigo (Passo Fundo, RS). Plantio direto no Brasil. Passo Fundo, Aldeia Norte, 1993. p.19-28.

EMPRESA BRASILEIRA DE PESQUISA AGROPECUÁRIA EMBRAPA. Centro Nacional de Pesquisa de Solos. Manual de métodos de análise de solo. 2.ed. Brasília, 1997. 212p. (EMBRAPA CNPS. Documentos, 1) 
EMPRESA BRASILEIRA DE PESQUISA AGROPECUÁRIA EMBRAPA. Centro Nacional de Pesquisa de Solos. Sistema brasileiro de dlassificação de sol os. Rio deJ aneiro, 1999. 312p.

MACEDO, M.C.M. Integração lavoura e pecuária: alternativa para sustentabilidade da produção animal. In: SI MPÓSIO SOBRE MANEJ O DA PASTAGEM, 18., Piracicaba, 2001. Anais. Piracicaba, Universidade de São Paulo, 2001. p.257283.

McGARRY, D.; BRIDGE, B.J . \& RADFORD, B.J . Contrasting soil physical properties after zero and traditional tillage of an alluvial soil in the semi-arid tropics. Soil Till. Res., 53:105-115, 2000.

OLIVEIRA, E.; MEDEIROS, G.B.; MARUN, F.; OLIVEIRA, J.C.; SÁ, J .P.G.; COLOZZI Fo, A.; KRANZ, W.M; SILVAJ r., N.F.; ABRAHÃO, J J.S.; GUERINI, V.L. \& MARTIN, G.L. Recuperação de pastagens no noroeste do Paraná: bases para o plantio direto e integração lavoura e pecuária. la.versão. Londrina, IAPAR, 2000. 96p. (IAPAR. Informe de Pesquisa, 134)

RESENDE, P.C.S. Resistência mecânica e sua variação com a umidade e com a densidade do sol o em L atossol o Vermel hoEscuro do Cerrado. Botucatú, Universidade Estadual de São Paulo, 1995. 64p. (Tese de Mestrado)

SALVIANO, A.A.C. Determinação de propriedades físicas de um solo Laterítico Bruno Avermelhado distrófico sob diferentes sistemas de cultivo. Porto Alegre, Universidade Federal do Rio Grande doSul, 1981. 55p (Tese de Mestrado)
SANTOS, H.P. \& TOMM, G.O. Rotação de culturas para trigo, após quatro anos: efeitos na fertilidade do solo em plantio direto. Ci. Rural, 29:259-265, 1999.

SAS INSTITUTE. SAS system for Microsoft Windows version 8.2. Cary, Statistical Analysis Systems, 2003.

SIQUEIRA, J .O.; MOREIRA, F.M.S.; GRISI, B.M.; HUNGRIA, M. \& ARAUJ O, R.S. Microrganismos e processos biológicos do solo: perspectiva ambiental. Brasília, EMBRAPA-SPI/ CNPAF, 1994. 142p. (EMBRAPA-CNPAF. Documentos, 45)

SPERA, S.T.; SANTOS, H.P.; FONTANELI, R.S.; KOCHHANN, R.A.; DENARDIN, J .E. \& SPERA, M.R.N. Soil compaction in southern Brazilian Oxisols under no-till system. In: INTERNATIONAL CONFERENCE ON LAND DEGRADATION, 3., Rio deJ aneiro, 2001. Proceedings. Rio de J aneiro, EMBRAPA-CNPS / Sociedade Brasileira de Ciência do Solo, 2002. p.1-3.

TORRES, E. \& SARAIVA, O.F. Camadas de impedimento mecânico do solo em sistemas agrícolas com a soja. Londrina, EMBRAPA CNPSo, 1999. 58p. (EMBRAPA CNPSo. Circular Técnica, 23)

TREIN, C.R.; COGO, N.P. \& LEVIEN, R. Métodos de preparo do solo na cultura do milho e ressemeadura do trevo, na rotação aveia +trevo/milho, após pastejo intensivo. R. Bras. Ci. Solo, 15:105-111, 1991.

UNGER, W.P. \& KASPAR, T.C. Compaction and root growth: a review. Agron. J ., 86:759-766, 1994. 